\title{
Investigation of the Effect of Polymeric Cement Modifier and Fibers on Properties of Fiber Reinforced Polymer Cement Composites by Surface Response Method
}

\author{
Arda Özen ${ }^{1}$, M.Hulusi Özkul ${ }^{2}$ \\ ${ }^{1}$ Istanbul Technical University, Department of Polymer Science and Technology \\ ${ }^{2}$ Istanbul Technical University, Civil Engineering Department \\ ozenar15@itu.edu.tr
}

\begin{abstract}
In this study, the affection of different ratios of water-cement, polymer-cement, fiber-cement and hybrid fibers on mortars have been examined. It has been observed mechanical, workability, fluidity and shrinkage properties of polymer modified mortars during experimental period. In experiments, polymeric additives such as acrylic-styrene resin, polycarboxylate eter based superplasticizer and shrinkage reducing agent, fibers such as $12 \mathrm{~mm}, 3 \mathrm{~mm}$ glass fibers, 6mm surface treated glass fiber, and polypropylene and nylon fibers have been used. A mathematical model was evaluated which is based on surface response model. Central composite design has been used as a design of experiment. The mortar specimens have been cured 2 days in water pool. After 60 days, their mechanical tests have been performed. As results of experiments, hybrid fibers improve flexural properties of mortars and also make positive effect on processability properties. Usage of single $12 \mathrm{~mm}$ glass fibers and $6 \mathrm{~mm}$ surface treated glass fibers have better effect on compressive properties than hybrid fibers. Usage of high amount of styrene-acrylic cement modifier has affected the mechanical strength negatively.
\end{abstract}

Keywords: Polymer cement composite, acrylic-styrene cement modifier, surface response method, fibers

\section{Introduction}

It is known very well that cement composites are one of the very important construction materials for safe buildings and strong constructions. Because of their wide usage, variety of technical researches are being done in this field. But there are also needs for further modification and analysis of cement mortars and concretes to develop this material for future applications and according to needs of humans. Cement mortars are one of the most commonly used structural material but it has some drawbacks such as brittleness, low flexibility and ductility [1]. These drawbacks can be overcome by using polymeric cement modifiers [2] and fibers [3].

In this paper, influences of styrene-acrylic cement modifier, water and glass fibers have been examined through surface response method. Central composite design has been used as a design of experiment. It is known that hybrid fiber reinforced cement composites exhibit higher flexural strength [4-5] and it is expected that hybrid fibered specimens exhibit better mechanical properties which may not be observed in single fibered reinforced cement composites. [6] Therefore, 3 hybrid fibered specimens such as (12 mm glass fiber with polypropylene fiber), (12 $\mathrm{mm}$ glass fiber with nylon fiber) and (12 $\mathrm{mm}$ glass fiber with $3 \mathrm{~mm}$ glass fiber) have been produced to compare single fibered (12 mm glass fiber) specimens. In one of the mixture $6 \mathrm{~mm}$ surface treated glass fibers have been used. Flow table tests have been performed to learn liquidity of specimens. Flexural and compression tests have been performed to learn their mechanical behaviors and weight loss of specimens have been measured during this period to learn their shrinkage properties. It is aimed to gain extensive knowledge by mathematical models with each tests and in this way it has been compared the results of hybrid and single fibered mixtures. 


\section{Experimental}

\subsection{Materials}

In all experiments, Çimsa 52.5 R white cement, 60-70 silica sand (ÇELIKKTAŞ), $30 \mu \mathrm{m}$ calcite(ESEN), Hydroxyethyl cellulose (Tylose H300 P2), different amount of fibers in different mixtures such as, $12 \mathrm{~mm}$ glass fiber (Anti Crack HP 12), $3 \mathrm{~mm}$ glass fiber (Cem-FIL Anti-Crack AR), $6 \mathrm{~mm}$ surface treated glass fiber(Şişecam),3 mm polypropylene fiber (polyfibers), different amount of styrene-acrylic cement modifier (BASF Acronal S 400), polycarboxylate eter based superplasticizer (Sika ViscoCrete Hi-Tech 30) and shrinkage reducing agent (Sika Control 40) have been used.

\subsection{Mixture Design and Mathematical Model}

The mixture proportions have been determined according to surface response method. The design of experiment is 3 variable central composite design (CCD). The factors are water-cement, polymer-cement and fibers-cement ratios. Codified factors are given in Table 1.

TABLE 1: Codified Values of Mathematical Model.

\begin{tabular}{lccccc}
\hline \hline Factors & \multicolumn{5}{c}{ Coded Value } \\
\cline { 2 - 6 } & -1.68 & -1 & 0 & 1 & 1.68 \\
\hline $\mathrm{X}_{1}=$ water/cement ratio & 0.47 & 0.54 & 0.64 & 0.74 & 0.81 \\
$\begin{array}{l}\mathrm{X}_{2}=\text { polymer/cement } \\
\text { ratio }\end{array}$ & $6.6 \%$ & $10 \%$ & $15 \%$ & $20 \%$ & $23.4 \%$ \\
$\mathrm{X}_{3}=$ fiber/cement ratio & $0.5 \%$ & $0.9 \%$ & $1.5 \%$ & $2.1 \%$ & $2.5 \%$ \\
\hline \hline
\end{tabular}

\subsection{Production Process}

Each of the specimen has been produced according to this process:

Step 1: 500 gr cement+ 600 gr Sand +100 gr Calcite + Fibers +2 gr Cellulose are mixed.

Step 2: $30 \%$ of water and superplasticizer are mixed.

Step 3: $70 \%$ of water are added to mixture of cement, sand, calcite, fibers and cellulose and they are mixed in cement mixture together.

Step 4: In the pause during transition to high speed mixing, shrinkage agent and water-superplasticizer and polymeric resins are added to pre-mixture.

After the production of fresh mortars, flow table tests have been performed. EYL-C208 type flow table has been used in flow test. After flow table test, the fresh mortars have been molded for 24 hours. After 24 hours of molding, the cement mortar specimens have been removed from molds and they have been cured in water pool for 2 days. Totally, 60 days have been waited after production of specimens. The specimens are 40x40x $160 \mathrm{~mm}^{3}$. At the end of 60 days period, three point flexural and compression tests have been performed at MTS Criterion 64.305 type of machine. After production, curing and at the end of 60 days of production, the specimens have been weighed and the weight loss of specimens have been calculated through this process. The amounts of ingredients are given in Table 2. 
TABLE II: Experimental Designs and Amount of Materials Used in Mixtures.

\begin{tabular}{|c|c|c|c|c|c|c|c|c|c|c|c|}
\hline $\begin{array}{l}\text { Run } \\
\text { name }\end{array}$ & w/c & $\overline{\mathrm{p} / \mathrm{c}}$ & $\begin{array}{l}\mathrm{f} / \mathrm{c} \\
(\%)\end{array}$ & $\begin{array}{l}60-70 \\
\text { Silica } \\
\text { Sand } \\
\end{array}$ & Cement & Calcite & Cellulose & $\begin{array}{l}\text { Fiber } \\
\text { Glass } \\
\text { (gr) }\end{array}$ & $\begin{array}{l}\text { Fiber } \\
\text { PP } \\
\text { (gr) } \\
\end{array}$ & $\begin{array}{l}\text { Fiber PA } \\
\text { (gr) }\end{array}$ & $\begin{array}{l}\text { Sp\&Sa }{ }^{* *+} \\
(\% / \%)\end{array}$ \\
\hline Run 2 & 0.47 & $15 \%$ & 1.5 & $600 \mathrm{~g}$ & $500 \mathrm{~g}$ & $100 \mathrm{~g}$ & $2 \mathrm{gr}$ & 7.5 & & & $1 / 1.5$ \\
\hline Run 5 & 0.54 & $10 \%$ & 2.1 & $600 \mathrm{~g}$ & $500 \mathrm{~g}$ & $100 \mathrm{~g}$ & $2 \mathrm{gr}$ & 10.5 & & & $1 / 1.5$ \\
\hline Run 11 & 0.54 & $10 \%$ & 0.9 & $600 \mathrm{~g}$ & $500 \mathrm{~g}$ & $100 \mathrm{~g}$ & $2 \mathrm{gr}$ & 4.5 & & & $1 / 1.5$ \\
\hline Run 10 & 0.54 & $20 \%$ & 2.1 & $600 \mathrm{~g}$ & $500 \mathrm{~g}$ & $100 \mathrm{~g}$ & $2 \mathrm{gr}$ & 10.5 & & & $1 / 1.5$ \\
\hline Run 15 & 0.54 & $20 \%$ & 0.9 & $600 \mathrm{~g}$ & $500 \mathrm{~g}$ & $100 \mathrm{~g}$ & $2 \mathrm{gr}$ & 4.5 & & & $1 / 1.5$ \\
\hline Run 8 & 0.64 & $6.6 \%$ & 1.5 & $600 \mathrm{~g}$ & $500 \mathrm{~g}$ & $100 \mathrm{~g}$ & $2 \mathrm{gr}$ & 7.5 & & & $1 / 1.5$ \\
\hline Run 1 & 0.64 & $15 \%$ & 1.5 & $600 \mathrm{~g}$ & $500 \mathrm{~g}$ & $100 \mathrm{~g}$ & $2 \mathrm{gr}$ & 7.5 & & & $1 / 1.5$ \\
\hline Run 9 & 0.64 & $15 \%$ & 0.5 & $600 \mathrm{~g}$ & $500 \mathrm{~g}$ & $100 \mathrm{~g}$ & $2 \mathrm{gr}$ & 2.5 & & & $1 / 1.5$ \\
\hline Run 13 & 0.64 & $15 \%$ & 2.5 & $600 \mathrm{~g}$ & $500 \mathrm{~g}$ & $100 \mathrm{~g}$ & $2 \mathrm{gr}$ & 12.5 & & & $1 / 1.5$ \\
\hline Run 6 & 0.64 & $23.4 \%$ & 1.5 & $600 \mathrm{~g}$ & $500 \mathrm{~g}$ & $100 \mathrm{~g}$ & $2 \mathrm{gr}$ & 7.5 & & & $1 / 1.5$ \\
\hline Run 4 & 0.74 & $10 \%$ & 0.9 & $600 \mathrm{~g}$ & $500 \mathrm{~g}$ & $100 \mathrm{~g}$ & $2 \mathrm{gr}$ & 4.5 & & & $1 / 1.5$ \\
\hline Run 12 & 0.74 & $10 \%$ & 2.1 & $600 \mathrm{~g}$ & $500 \mathrm{~g}$ & $100 \mathrm{~g}$ & $2 \mathrm{gr}$ & 10.5 & & & $1 / 1.5$ \\
\hline Run 14 & 0.74 & $20 \%$ & 0.9 & $600 \mathrm{~g}$ & $500 \mathrm{~g}$ & $100 \mathrm{~g}$ & $2 \mathrm{gr}$ & 4.5 & & & $1 / 1.5$ \\
\hline Run 3 & 0.74 & $20 \%$ & 2.1 & $600 \mathrm{~g}$ & $500 \mathrm{~g}$ & $100 \mathrm{~g}$ & $2 \mathrm{gr}$ & 10.5 & & & $1 / 1.5$ \\
\hline Run 7 & 0.81 & $15 \%$ & 1.5 & $600 \mathrm{~g}$ & $500 \mathrm{~g}$ & $100 \mathrm{~g}$ & $2 \mathrm{gr}$ & 7.5 & & & $1 / 1.5$ \\
\hline H1 & 0.64 & $15 \%$ & 2 & $600 \mathrm{~g}$ & $500 \mathrm{~g}$ & $100 \mathrm{~g}$ & $2 \mathrm{gr}$ & 5 & 5 & & $1 / 1.5$ \\
\hline $\mathrm{H} 2$ & 0.64 & $15 \%$ & 2 & $600 \mathrm{~g}$ & $500 \mathrm{~g}$ & $100 \mathrm{~g}$ & $2 \mathrm{gr}$ & 5 & & 5 & $1 / 1.5$ \\
\hline $\mathrm{H} 3$ & 0.64 & $15 \%$ & 2 & $600 \mathrm{~g}$ & $500 \mathrm{~g}$ & $100 \mathrm{~g}$ & $2 \mathrm{gr}$ & $10^{*}$ & & & $1 / 1.5$ \\
\hline $\mathrm{H} 4$ & 0.64 & $15 \%$ & 2 & $600 \mathrm{~g}$ & $500 \mathrm{~g}$ & $100 \mathrm{~g}$ & $2 \mathrm{gr}$ & $10^{* *}$ & & & $1 / 1.5$ \\
\hline
\end{tabular}

* H3 specimens have been produced with $6 \mathrm{~mm}$ surface treated glass fibers.

${ }^{* * *} \mathrm{H} 4$ specimens have been produced with $5 \mathrm{~g}$ of $3 \mathrm{~mm}$ and $5 \mathrm{~g}$ of $12 \mathrm{~mm}$ fiber

Sp\&Sa is the percent ratio of superplasticizer and shrinkage reducing agent.

\section{Result and Discussion}

The results of flow tests, three point flexural tests, compression tests and weight loss tests have been given in Table III. Flow test results have defined that, increasing fiber/cement ratio has decreased the fluidity and the workability of specimens. It can be easily observed with the comparison of run 4 and run 12.The affection of polypropylene and nylon fibers to flow results of fresh mortar has been almost the same. Surface treated fibers have positive effect on flow tests. Although $2 \%$ surface treated glass fibers have been added to H3, $27 \mathrm{~cm}$ flow result has been obtained which has been relatively high when compared with $12 \mathrm{~mm}$ glass fibered specimens. Treated surface of these glass fibers have enabled homogenous and better distribution of fresh mortar. Therefore, H3 specimens have been the most strength specimens according to three point flexural and compression tests. This situation has explained the relation between mechanical strength and surface interaction of fibers with matrix materials. The polymeric cement modifier which used in the experiments has approximately $51 \%$ water content. It has been observed that, increasing polymer content has increased the flow results. Polymeric phase generation and hydration of cement particles are very important for creation of monolithic matrix phases in cement composites [2]. But usage of high amount of water and polymeric cement modifiers has increased weight loss of specimens in time. According to weight loss results, the specimens which have high polymer and high water content, have lost their weight in higher amounts during this period. This has caused more porosity and lower mechanical strength in those specimens. The flexural test results have shown that the highest flexural strength has been achieved in H3 (10.28 MPa). The other most strength mixtures have been H1 (polypropylene and $12 \mathrm{~mm}$ glass fibered mixture), $\mathrm{H} 2$ (nylon and $12 \mathrm{~mm}$ glass fibered mixture) and $\mathrm{H} 4$ (12 $\mathrm{mm}$ and $3 \mathrm{~mm}$ glass fibered mixture). Their strength has been higher than even the mixtures contained lower amount of water. These results proved the importance of hybrid fibers.

The most strength single fibered mixture has been Run $11(8.49 \mathrm{MPa})$. It has got $0.54 \mathrm{w} / \mathrm{c}, 10 \% \mathrm{p} / \mathrm{c}$ and $0.9 \% \mathrm{f} / \mathrm{c}$. It has been seen that flexural strength has decreased when fiber content increases from $0.9 \%$ to $2.1 \%$ whereas $0.9 \%$ glass fiber content is a low ratio. One of the important reason of this situation might be balling effect of fibers. Low workability and processing conditions may be the reason of this situation. In comparison of Run 11 and Run 15, it has been observed that flexural strength has been decreased with increasing polymer content from $10 \%$ to $20 \%$. This situation has been already reported in other studies [7-8]. According to compressive test results, the most strength mixture has been H3 (26.90 MPa). The highest compressive strength of $12 \mathrm{~mm}$ glass fibered mixture has been Run 11 with $25.21 \mathrm{MPa}$ again. Increasing fiber/cement ratio 
has affected the compressive strength negatively. In compression tests, the results of hybrid specimens have been quite high in comparison of the other specimens but the conditions have not been equal with flexural results. It is possible to express that, glass fibers have been more effective to improve compressive strength than hybrid fibers. The whole mixtures have been determined according to mathematical model. Usage of mathematical model makes it possible to predict the test results in the range of codified values. Summary of the mathematical models are given in Table IV.

TABLE III: Results of Experiments.

\begin{tabular}{llllllll}
\hline \hline Run name & w/c & $\mathrm{p} / \mathrm{c}$ & $\mathrm{f} / \mathrm{c}$ & $\begin{array}{l}\text { Flexural } \\
\text { Strength(MPa) }\end{array}$ & $\begin{array}{l}\text { Compressive } \\
\text { Strength (MPa) }\end{array}$ & $\begin{array}{l}\text { Weight Loss } \\
(\%)\end{array}$ & Flow (cm) \\
\hline Run 1 & 0 & 0 & 0 & 7.72 & 22.78 & $7.22 \%$ & 23.5 \\
Run 2 & -1.68 & 0 & 0 & 7.88 & 20.30 & $5.15 \%$ & 19 \\
Run 3 & 1 & 1 & 1 & 6.74 & 14.84 & $10.18 \%$ & 25 \\
Run 4 & 1 & -1 & -1 & 7.85 & 19.27 & $9.52 \%$ & 30 \\
Run 5 & -1 & -1 & 1 & 7.57 & 23.87 & $6.72 \%$ & 16 \\
Run 6 & 0 & 1.68 & 0 & 7.02 & 15.22 & $8.97 \%$ & 24.5 \\
Run 7 & 1.68 & 0 & 0 & 6.78 & 17.75 & $12.11 \%$ & 31 \\
Run 8 & 0 & -1.68 & 0 & 7.78 & 22.25 & $7.20 \%$ & 19 \\
Run 9 & 0 & 0 & -1.68 & 7.94 & 21.95 & $7.14 \%$ & 27 \\
Run 10 & -1 & 1 & 1 & 6.77 & 16.50 & $7.13 \%$ & 22 \\
Run 11 & -1 & -1 & -1 & 8.48 & 25.21 & $5.67 \%$ & 22.5 \\
Run 12 & 1 & -1 & 1 & 7.30 & 14.40 & $9.79 \%$ & 24 \\
Run 13 & 0 & 0 & 1.68 & 6.63 & 17.98 & $7.92 \%$ & 20 \\
Run 14 & 1 & 1 & -1 & 7.11 & 18.305 & $11.83 \%$ & 27 \\
Run 15 & -1 & 1 & -1 & 7.91 & 19.04 & $7.18 \%$ & 24 \\
Run 16 & 0 & 0 & 0 & 7.5 & 23.01 & $8.22 \%$ & 23 \\
Run 17 & 0 & 0 & 0 & 7.48 & 23.00 & $7.96 \%$ & 23 \\
Run 18 & 0 & 0 & 0 & 7.63 & 22.83 & $7.95 \%$ & 23 \\
H1 & 0.64 & $15 \%$ & $\% 2$ & 9.48 & 21.79 & $8.46 \%$ & 22 \\
H2 & 0.64 & $15 \%$ & $\% 2$ & 9.14 & 21.39 & $9.10 \%$ & 22.5 \\
H3 & 0.64 & $15 \%$ & $\% 2$ & 10.28 & 26.90 & $8.37 \%$ & 27 \\
H4 & 0.64 & $15 \%$ & $\% 2$ & 9.56 & 22.81 & $9.11 \%$ & 22.5 \\
\hline \hline
\end{tabular}

TABLE IV: Summaries of Mathematical Models.

\begin{tabular}{|c|c|c|c|c|c|c|c|c|}
\hline \multirow[b]{2}{*}{ Factor } & \multicolumn{2}{|c|}{$\begin{array}{l}\text { Flexural Tests } \\
\left(\mathrm{R}^{2}=95.44 \%\right) \\
\left(\mathrm{R}^{2} \operatorname{adj}=90.31 \%\right)\end{array}$} & \multicolumn{2}{|c|}{$\begin{array}{l}\text { Compression Tests } \\
\left(\mathrm{R}^{2}=95.37 \%\right) \\
\left(\mathrm{R}^{2} \mathrm{adj}=90.17 \%\right)\end{array}$} & \multicolumn{2}{|c|}{$\begin{array}{l}\text { Weight Loss } \\
\left(\mathrm{R}^{2}=97.32 \%\right) \\
\left(\mathrm{R}^{2} \text { adj }=94.30 \%\right)\end{array}$} & \multicolumn{2}{|c|}{$\begin{array}{l}\text { Flow Tests } \\
\left(\mathrm{R}^{2}=97.41 \%\right) \\
\left(\mathrm{R}^{2} \mathrm{adj}=94.49 \%\right)\end{array}$} \\
\hline & Coefficient & P-Value & Coefficient & P-Value & Coefficient & P-Value & Coefficient & P-Value \\
\hline Constant & 3233.3 & 0.000 & 36638 & 0.000 & 7.818 & 0.000 & 23.107 & 0.000 \\
\hline$X_{1}$ & -113.0 & 0.000 & -2591 & 0.000 & 1.928 & 0.000 & 3.052 & 0.000 \\
\hline$X_{2}$ & -123.0 & 0.000 & -3032 & 0.000 & 0.556 & 0.002 & 1.080 & 0.002 \\
\hline $\mathrm{X}_{3}$ & -161.8 & 0.000 & -2212 & 0.001 & 0.068 & 0.591 & -2.070 & 0.000 \\
\hline $\mathrm{X}_{1}{ }^{2}$ & -26.1 & 0.212 & -2222 & 0.002 & 0.368 & 0.020 & 0.745 & 0.017 \\
\hline $\mathrm{X}_{2}^{2}$ & -14.3 & 0.479 & -2382 & 0.001 & 0.175 & 0.204 & -0.404 & 0.142 \\
\hline $\mathrm{X}_{3}^{2}$ & -31.8 & 0.138 & -1687 & 0.007 & -0.021 & 0.874 & 0.214 & 0.412 \\
\hline $\mathrm{X}_{1} \mathrm{X}_{2}$ & 4.1 & 0.869 & 2605 & 0.002 & 0.097 & 0.558 & -1.187 & 0.005 \\
\hline $\mathrm{X}_{1} \mathrm{X}_{3}$ & 60.6 & 0.037 & -889 & 0.173 & -0.298 & 0.099 & 0.062 & 0.846 \\
\hline $\mathrm{X}_{2} \mathrm{X}_{3}$ & -2.6 & 0.916 & 41 & 0.947 & -0.378 & 0.045 & 1.063 & 0.009 \\
\hline
\end{tabular}

Commercially available software has been used for surface response method. The software has been performed nonlinear regression for responses. By this method, it is possible to obtain surfaces and equations for each methods. $\mathrm{P}$ value is important for understanding the significance of a parameter. If $\mathrm{p}<0.05$, it means that this parameter is significant. The surfaces of test responses are given in Figure (1-4). Stress-deflection curves of flexural and compression tests are given in Figure (5-6). 

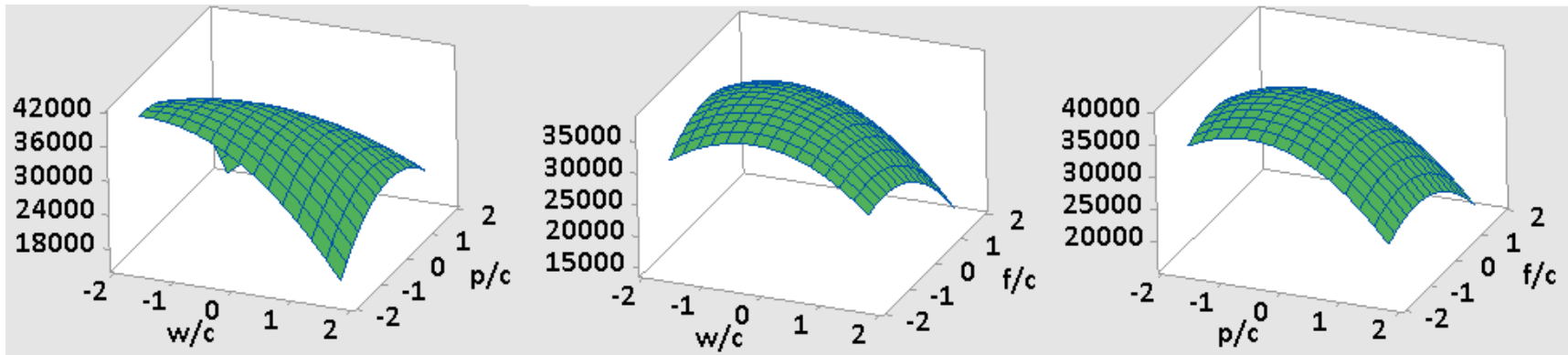

Fig. 1: Surfaces of compression test results (N).

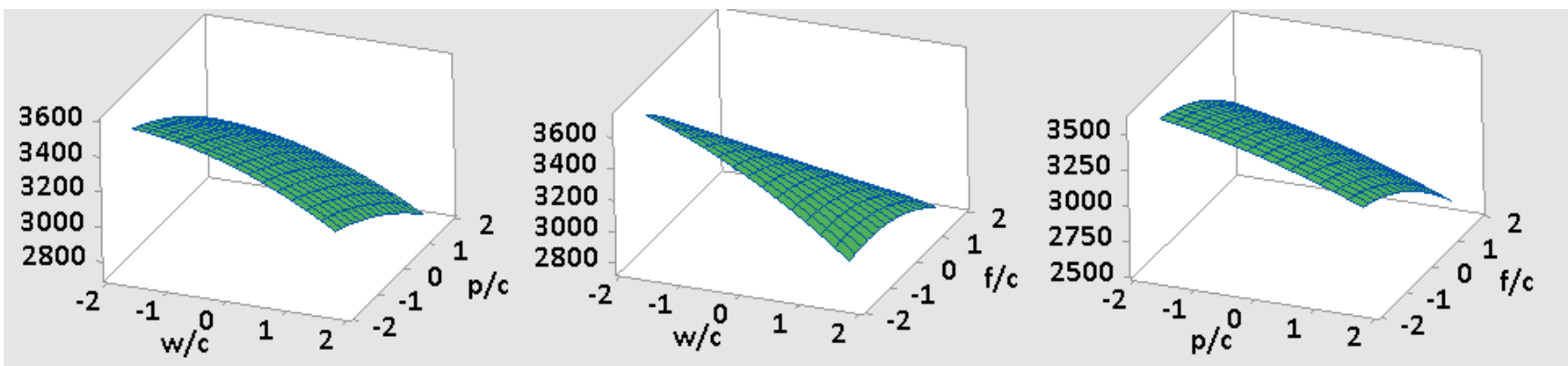

Fig. 2: Surfaces of Flexural Test Results (N).

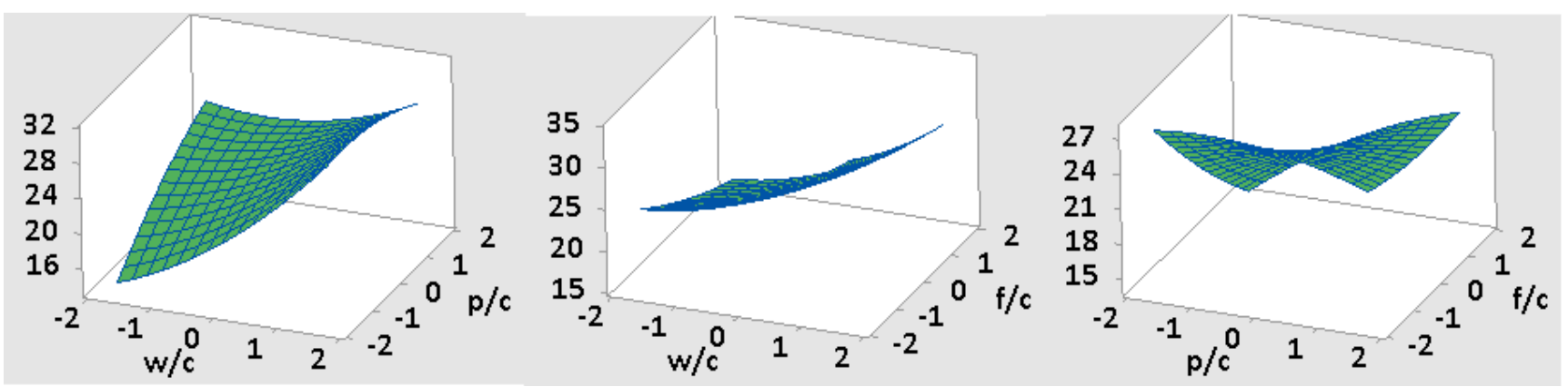

Fig. 3: Surfaces of Flow Table Test Results (cm).
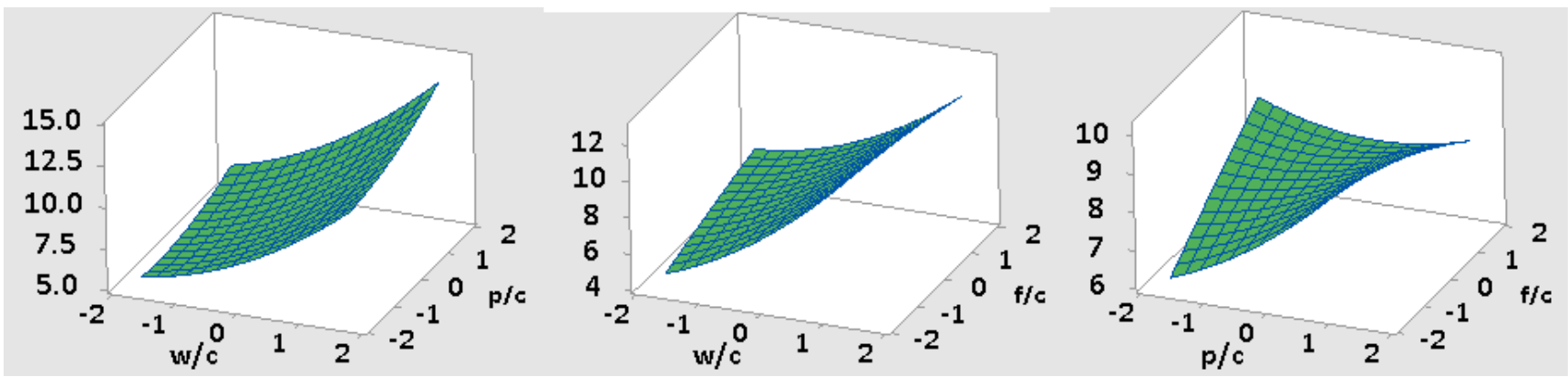

Fig. 4: Surfaces of Weight Loss Results (\%). 

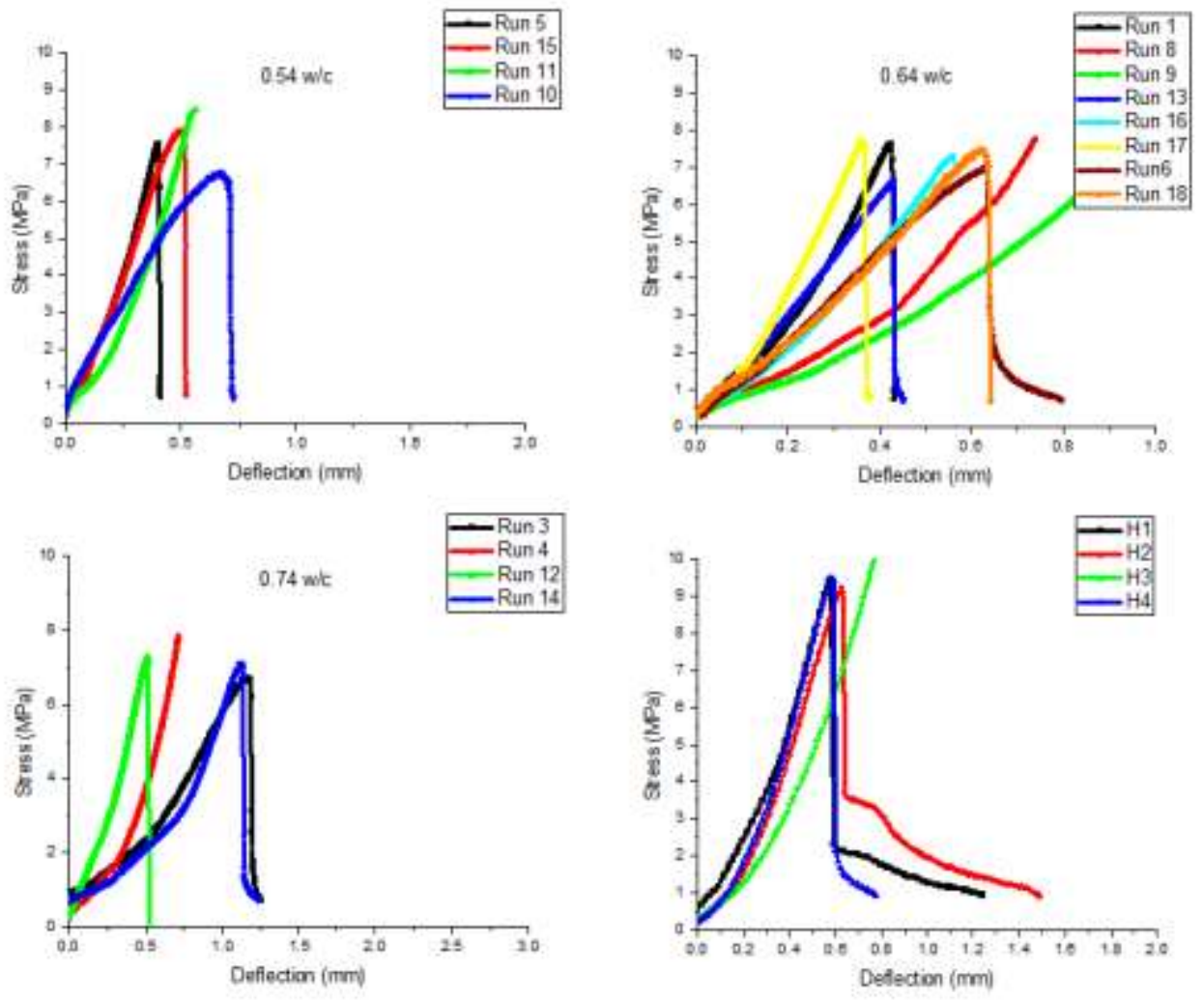

Fig. 5: Flexural stress-deflection curves of $0.54,0.64,0.74 \mathrm{w} / \mathrm{c}$ ratio and hybrid specimens.
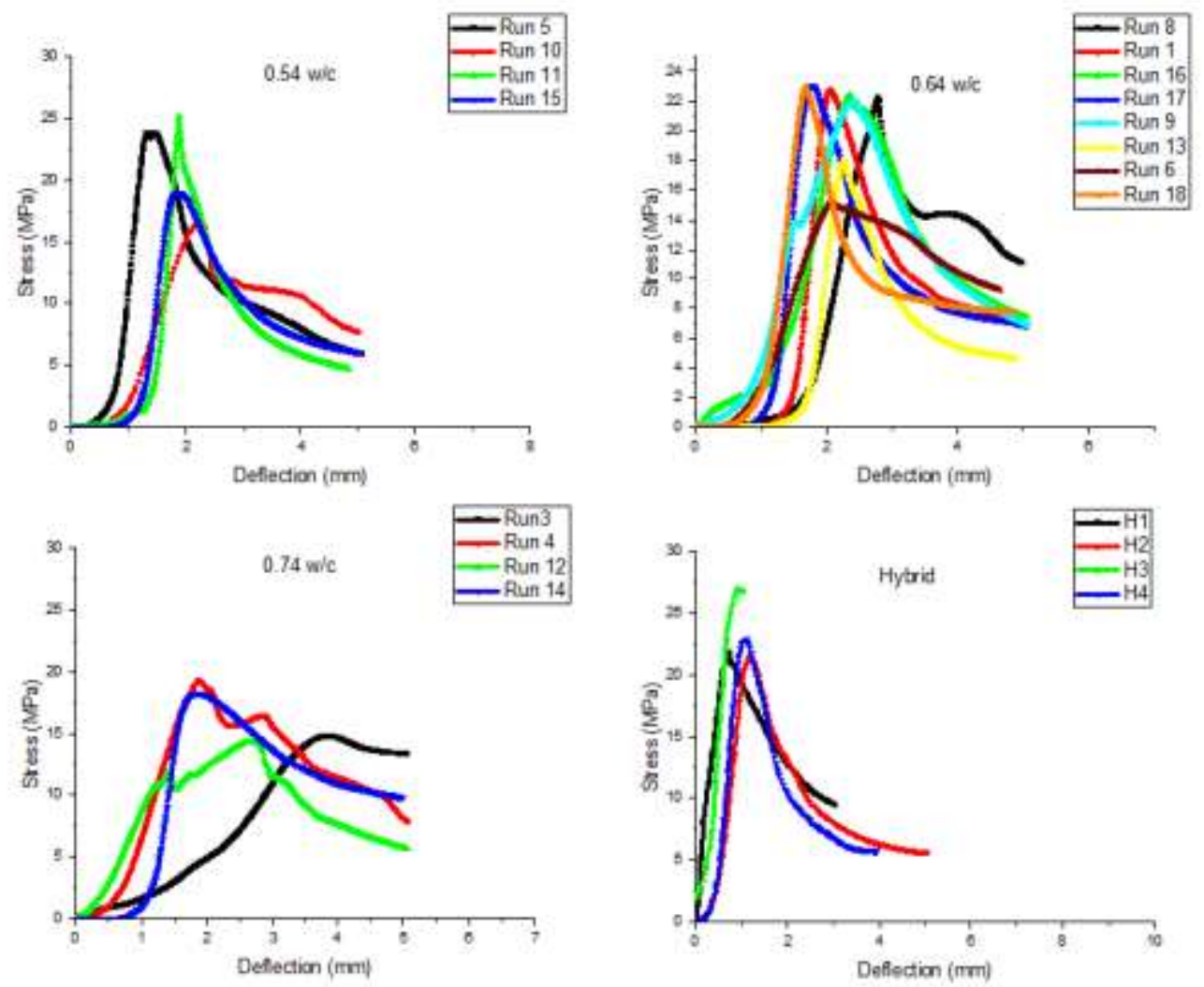

Fig. 6: Compressive stress-deflection curves of $0.54,0.64,0.74 \mathrm{w} / \mathrm{c}$ ratio and hybrid specimens. 


\section{Conclusion and Recommendation}

First, it is clear that there has been a critical value of polymeric modifiers used in mortars. Increasing polymer content from $10 \%$ to $20 \%$, has been decreased both of flexural and compressive strength of mortars. This situation has been observed at all mixtures. Second, it has been observed that increasing fiber ratio has decreased flexural strength, compressive strength and flow table results. The best mechanical results have been obtained with $0.9 \%$ fiber content in single $12 \mathrm{~mm}$ glass fibered specimens. By changing mixing processes or by using better production methods, it is possible to use higher content of fibers in mixtures. It has been observed that, mechanical properties of mortars have been more sensitive to increasing polymer content rather than increasing fiber content. Finally, the flexural results of hybrid fibered specimens have been relatively higher than single fibered specimens. These results show that hybrid fibers can be good choice to increase flexural strength. But the same positive effect cannot be observed for compression test results. It is important that high flexural test results of hybrid fibered specimens have been achieved with $2 \% \mathrm{f} / \mathrm{c}$ where balling effect of single fibers has decreased the strength of specimens. Therefore it is apparent that combination of different fibers and different length of fibers synergism has been observed and hence the flexural strength has increased. According to these results, combinations of different fibers have good potentials to achieve higher flexural properties. More hybrid fibered, polymer modified cement mortars and concretes should be produced and their contribution on properties should be further investigated.

\section{References}

[1] Chen, W., Zhong, S. Influences of Processing and Testing Conditions on Flexural Behavior of Fiber-reinforced Polymer-modified Cement Mortar, Advanced Materials Research, vol. 687,pp. 502-507, 2013.

[2] Ohama, Y. Handbook of Polymer Modified Concrete and Mortars, Noyes Publications, USA, 1995, ch 2, pp 17-18.

[3] Pakravan, H. R., Jamshidi, M., Latif, M., Pacheco-Torgal, F. Influence of Acrylic Fibers Geometry on the Mechanical Performance of Fiber-Cement Composites, Journal of Applied Polymer Science, vol. 125, pp. 3050-3057, 2012.

[4] Banthia, N., Nandakumar, N. Crack growth resistance of hybrid fiber reinforced cement composites, Cement and Concrete Composites, vol. 25, pp. 3-9, 2003.

[5] Qian, C. X., Stroeven, P. Development of hybrid polypropylene-steel fiber-reinforced concrete, Cement and Concrete Research, 30, 63-69, 2000.

[6] Jung, J., Park, C., Park, P. Bond Properties of Structural Polypropylene Fiber in Hybrid Nonstructural Polypropylene and Structural Polypropylene Fiber-Reinforced Latex Modified Cement-Based Composites, Journal of Applied Polymer Science, 127, 1221-1227, 2013.

[7] Li, G., Zhao, X., Rong, C., Wang, Z. Properties of polymer modified steel fiber-reinforced cement concretes, Construction and Building Materials, 24, 1201-1206, 2010.

[8] Jung, J., Lee, J., Park, C. Effect of Styrene-Butadiene Latex on the Bond Performance of Macro Synthetic Fiber in Jute/Macro Synthetic Hybrid Fiber- Reinforced Latex-Modified Cement-Based Composites, Journal of Applied Polymer Science, 127, 3522-3529, 2013. 